\title{
Incidence and related risk factors of radiographic knee osteoarthritis: a population-based longitudinal study in China
}

Liyi Zhang ${ }^{1,2+}$, Chutong Lin ${ }^{1,2,3 \dagger}$, Qiang Liu ${ }^{1,2 \dagger}$, Jiaxiang Gao ${ }^{1,2}$, Yunfei Hou ${ }^{1,2}$ and Jianhao Lin $^{1,2^{*}}$ (D)

\begin{abstract}
Objective: To explore the incidence and risk factors for radiographic knee osteoarthritis (ROA) in a suburban area of China.

Methods: Shunyi Osteoarthritis Study was a population-based, longitudinal study of knee osteoarthritis in Shunyi, a suburban area of Beijing, China. A total of 1295 residents aged over 50 years were recruited with fully informed by randomized cluster sampling and were followed up 3 years later. At the time of baseline and follow-up visits, participants completed a home interview questionnaire and received a clinical examination including height, weight, range of motion (ROM), chair stand test, 50-foot walk test, and weight-bearing posterior-anterior semiflexed view of radiographs at tibiofemoral joints. The incident $\mathrm{ROA}$ for a knee was defined if its $\mathrm{KL}$ grade was no more than grade 1 at baseline visit and no less than grade 2 at the follow-up visit. A patient without ROA in both knees at the baseline visit and with ROA in at least one knee at the follow-up visit was viewed as an incident case of ROA in patient level. Generalized linear model and generalized estimating equation were performed to examine the association between socio-demographic factors, physical function as well as baseline knee joint condition, and incident ROA in patient and knee level.
\end{abstract}

Results: A total of 1295 residents were recruited at baseline in 2014, and 962 (74.3\%) residents were followed in 2017. The annual cumulative incidence of ROA was 3.6\% at knee level and 5.7\% at patient level. Older age (per year, adjusted odds ratio $(\mathrm{OR})=1.079 ; 95 \%$ confidence interval $(\mathrm{Cl}), 1.042-1.117)$, overweight (adjusted $\mathrm{OR}=2.086$; $95 \% \mathrm{Cl}, 1.286-3.385$ ), female (adjusted $\mathrm{OR}=1.756 ; 95 \% \mathrm{Cl}, 1.074-2.877$ ), less $\mathrm{ROM}$ (per degree, adjusted $\mathrm{OR}=0.952$; 95\% Cl, 0.923-0.983) and Kellgren and Lawrence $(\mathrm{KL})$ grade 1 at baseline (adjusted $\mathrm{OR}=8.527 ; 95 \% \mathrm{Cl}, 5.489-13.246$ ) were risk factors for incident $\mathrm{ROA}$.

Conclusion: The incidence of knee ROA in Chinese suburban area was high. Advanced age, female, overweight, less range of motion, and $\mathrm{KL}$ grade 1 at baseline were associated with an increased risk of incident ROA.

Keywords: Knee osteoarthritis, Incidence, Risk factors, Radiograph

\footnotetext{
* Correspondence: linjianhao@pkuph.edu.cn

'Liyi Zhang, Chutong Lin, and Qiang Liu are co-first authors.

'Arthritis Clinic and Research Center, Peking University People's Hospital,

Peking University, No. 11 Xizhimen South Road, Xicheng District, Beijing

100044, China

${ }^{2}$ Arthritis Institute, Peking University, Beijing, China

Full list of author information is available at the end of the article
}

C C The Author(s). 2021 Open Access This article is licensed under a Creative Commons Attribution 4.0 International License, which permits use, sharing, adaptation, distribution and reproduction in any medium or format, as long as you give appropriate credit to the original author(s) and the source, provide a link to the Creative Commons licence, and indicate if changes were made. The images or other third party material in this article are included in the article's Creative Commons licence, unless indicated otherwise in a credit line to the material. If material is not included in the article's Creative Commons licence and your intended use is not permitted by statutory regulation or exceeds the permitted use, you will need to obtain permission directly from the copyright holder. To view a copy of this licence, visit http://creativecommons.org/licenses/by/4.0/ The Creative Commons Public Domain Dedication waiver (http://creativecommons.org/publicdomain/zero/1.0/) applies to the data made available in this article, unless otherwise stated in a credit line to the data. 


\section{Introduction}

Knee osteoarthritis (OA) is one of the most prevailing forms of osteoarthritis, causing pain, stiffness, deformity, and functional disability, which further leads to cardiovascular events and increases all-cause mortality [1-3].

Obesity and aging have long been shown to be strong risk factors for the incidence and progression of knee osteoarthritis. With the aging population and increase prevalence of obesity, this disorder and total knee replacement have become substantially more common in recent decades [4]. According to the 2010 Global Burden of Diseases study, the burden of OA is increasing most rapidly among musculoskeletal disorders in terms of disability-adjusted life years, which will impose new challenges on health system [5]. Early detection and prevention of knee $\mathrm{OA}$ is very important. However, there has been a gap between research and clinical practice in the field of prevention of knee OA. Filling this gap has been increasingly emphasized according to the concept of translational orthopedics [6]. Therefore, it is of necessity to understand the epidemiology of knee OA and identify the associated demographic factors.

Although a large number of potential risk factors for incident radiographic knee OA have been studied, most of those studies were performed in European population, and were limited by their cross-sectional design, and moreover some results are conflicting [7-9]. There were a few longitudinal studies on the risk factors of knee OA among Asian peoples, most of which were studied in Korea and Japan [10, 11]. Longitudinal population-based studies in Chinese population are rare, and the incidence and risk factors of OA in this large developing country are still unclear. We aimed to give the latest morbidity data and identify risk factors of knee OA in Chinese population, giving reference to medical policy makers.

The purpose of this population-based longitudinal study was to explore the incidence and risk factors for radiographic knee $\mathrm{OA}$ among the Chinese in suburban community.

\section{Subjects and methods \\ Subjects}

The Beijing Shunyi osteoarthritis study was a population-based, longitudinal, and prospective study of knee osteoarthritis, which was approved by the Ethics Committee of Peking University People's Hospital. The study was based on a random cluster sampling method in 2014. Fourteen villages in Shunyi District, Beijing, China, were selected, and every resident who participated in the survey had signed the informed consent document. The inclusion criteria for this study were (1) residence in Shunyi District, Beijing, and (2) age over 50 years. Exclusion criteria: (1) people with rheumatoid arthritis, (2) physically disability, (3) mental retardation,
(4) people with advanced malignant tumors or bedridden people, and (5) people recently living or working outside for more than 6 months. And the rejection criteria: (1) people who did not meet the inclusion criteria, (2) people who met the exclusion criteria, (3) people who failed to complete the main records, and (4) people who showed obvious incompatibility in the survey.

At the time of each visit, subjects completed a home interview questionnaire and received a clinical examination including height, weight, range of motion, chair stand test, 50foot walk test, and weight-bearing posterior-anterior semiflexed view of radiographs at tibiofemoral joints.

\section{Assessment of radiographic osteoarthritis}

Radiographic osteoarthritis (ROA) was assessed using the Kellgren and Lawrence $(\mathrm{KL})$ criteria $(0=$ none; $1=$ possible osteophytes only; 2 = definite osteophytes and possible joint space narrow (JSN); 3 = moderate osteophytes and/or definite JSN; and $4=$ large osteophytes, severe JSN, and/or bony sclerosis) [12]. Radiographic OA was defined as a KL grade of $\geq 2$, and the incident ROA for a knee was defined if its KL grade was no more than grade 1 at baseline visit and no less than grade 2 at the follow-up visit. A patient without ROA in both knees at the baseline visit and with ROA in at least one knee at the follow-up visit was viewed as an incident case of ROA in patient level.

Radiographs were read twice by two readers trained at Boston University, and films from Osteoarthritis Initiatives were used as gold standard as well as training material [13]. For each batch of Shunyi OA Study films ( $n$ $=100$ ), 10 films from the Osteoarthritis Initiatives study were added to test inter-reader reliability. In addition, 10 previously read knee radiographs from the Shunyi OA Study were fed back to the reader to test intra-reader reliability. Weighted kappa statistics for inter-reader and intra-reader reliability were 0.82 and 0.95 respectively.

\section{Assessment of covariates}

Demographic information, such as age, sex, education level, history of knee injury smoking, alcohol consumption, manual occupation, marriage, was collected at baseline using a standard questionnaire. Height was measured twice for each subject, using a wall-mounted stadiometer. Weight was assessed using a balance beam scale with a precision to $0.1 \mathrm{~kg}$. Body mass index (BMI) was calculated as weight in kilograms divided by height in meters squared. A subject with $\mathrm{BMI} \leq 25,25<\mathrm{BMI} \leq$ 30 , BMI > 30 was defined as normal, overweight and obesity, respectively. History of knee injury was identified by asking subjects "Have you ever suffered an injury in your knees causing a limitation of walking ability for at least one week?" The injured knee side and date of injury were recorded. Range of motion (ROM) and the 
degree of flexion contracture of the knee joints were assessed by goniometric measurements. A chair stand test was carried out using a 43-cm high, straight back armless chair. A full sit-to-stand and consecutive standto-sit cycle was counted as one chair stand, and the total time for 5 cycles was calculated by a well-trained examiner [14]. A 50-foot walk test was carried out by asking the participants to walk in a 25 -foot straight footpath and return back to the starting point as fast as possible. The total time was recorded [15].

\section{Statistical analysis}

All data was analyzed by $\mathrm{IBM}^{\bullet} \mathrm{SPSS}^{\circ}$ Statistics (Version 24.0) software and was presented as means \pm standard deviation (SD). Difference between follow-up group and non-follow-up group was assessed by independent samples $T$ test and chi-squared test. Generalized linear model (GLM) was performed to examine the association between factors (including age, sex, BMI, education levels, history of knee injury, chair stand test, 50-foot walk test) and incidence ROA in patient level. ROM, flexion contracture, knee pain, and KL grade at baseline were examined by generalized estimating equation (GEE) in knee level. A two-sided $P$ value 0.05 was considered statistically significant.

\section{Results \\ Participants}

A total of 1295 residents were recruited at the baseline in 2014, and 967 (74.7\%) were followed in 2017. Four hundred ninety-one residents suffered from one or both knee ROA at the baseline visit diagnosed by knee X-ray were excluded from the further incidence analysis. Of the remaining 803 residents, 598 residents received follow-up examination (follow-up rate $74.5 \%$, Table 1). The mean age of following subjects was $59.18 \pm 6.57$, of which $63.7 \%$ were female. The mean BMI was 25.96 (SD $=3.43)$. The mean knee $\mathrm{ROM}$ was 129.67 degrees $(\mathrm{SD}=$ 6.60). A total of 85 subjects had knee pain symptoms (14.3\%) (Table 1). Among 1196 knees without knee OA

Table 1 Baseline characteristic of participates

\begin{tabular}{|c|c|c|c|}
\hline Characteristic & Follow-up & Non-follow-up & $P$ value \\
\hline Total (\%) & $598(74.5 \%)$ & $205(25.5 \%)$ & \\
\hline \multicolumn{4}{|c|}{ Baseline socio-demographic, BMI, and history of knee injury } \\
\hline Age & $59.18 \pm 6.57$ & $61.48 \pm 8.52$ & $<0.01$ \\
\hline BMI & $25.96 \pm 3.43$ & $26.00 \pm 3.98$ & 0.283 \\
\hline \multicolumn{4}{|l|}{ Gender (\%) } \\
\hline Male & $217(36.3 \%)$ & $98(47.8 \%)$ & $<0.01$ \\
\hline Female & $381(63.7 \%)$ & $107(52.2 \%)$ & \\
\hline \multicolumn{4}{|l|}{ Education (\%) } \\
\hline Primary school & $136(22.7 \%)$ & $44(21.5 \%)$ & 0.705 \\
\hline Middle school or above & $462(77.3 \%)$ & $161(78.5 \%)$ & \\
\hline \multicolumn{4}{|l|}{ Injury (\%) } \\
\hline Yes & $30(5 \%)$ & $10(4.9 \%)$ & 0.937 \\
\hline No & $568(95 \%)$ & $195(95.1 \%)$ & \\
\hline \multicolumn{4}{|c|}{ Baseline physical function of the knee } \\
\hline Range of motion in knee level & $129.67 \pm 6.60$ & $129.70 \pm 7.44$ & 0.945 \\
\hline Flexion contracture in knee level & $1.23 \pm 2.21$ & $1.25 \pm 2.24$ & 0.898 \\
\hline 50-foot walk test & $12.68 \pm 2.62$ & $13.48 \pm 4.61$ & 0.02 \\
\hline Chair stand test & $8.45 \pm 2.19$ & $8.87 \pm 3.61$ & 0.115 \\
\hline \multicolumn{4}{|l|}{ Baseline knee condition } \\
\hline \multicolumn{4}{|l|}{ Baseline K/L grade in knee level (\%) } \\
\hline 0 & $776(64.9 \%)$ & $248(60.5 \%)$ & 0.11 \\
\hline 1 & $420(35.1 \%)$ & $162(39.5 \%)$ & \\
\hline \multicolumn{4}{|l|}{ Baseline knee pain (\%) } \\
\hline No pain & $513(85.8 \%)$ & $185(90.7 \%)$ & 0.188 \\
\hline One knee pain & $53(8.9 \%)$ & $11(5.4 \%)$ & \\
\hline Both knee pain & $32(5.4 \%)$ & $8(3.9 \%)$ & \\
\hline
\end{tabular}


at baseline, 776 knees had a KL of 0 , and 420 had a KL grade of 1 .

There was significant difference in age, gender, and walk speed tested by 50 -foot walk test between followup group and non-follow-up group. Older and male residents (mean age 61.48 \pm 8.52 years old, female accounted for $52.2 \%$ ) with poor walk ability tended to lose in the follow-up compared with the subjects who were successfully followed up.

\section{Incidence of radiographic osteoarthritis}

Incidence was calculated in both knee level and patient level. Five hundred ninety-eight subjects with 1196 knees without radiographic osteoarthritis at baseline were taken into analysis. After 3 years follow-up, 102 subjects with 128 knees developed radiographic osteoarthritis according to the X-ray result. The incidence of ROA was $10.7 \%$ (9.2\% in male and $11.5 \%$ in female) during 3 years (3.6\% annually) in knee level and $17.1 \%$ (14.3\% in male and $18.6 \%$ in female) during 3 years (5.7\% annually) in patient level. According to the statistical year book of Beijing Shunyi 2017, male villagers constituted $61.87 \%$ of the population in Zhaoquanying Town, for which the sex-standardized ROA incidence was 10.1\% (3.4\% annually) in knee level and $15.9 \%$ (5.3\% annually) in patient level. The number of the population and incidence of ROA by sex and age are shown in Fig. 1 . The incidence was much higher in females than males in all age groups. The incidence of ROA increased with age. However, after the age of 70 the incidence in male decreased and the rising trend of the incidence in females slowed down.

\section{Risk factors for radiographic osteoarthritis}

Table 2 and Fig. 2 showed the association between socio-demographic factors, physical function, baseline knee conditions, and incident ROA. In the univariate analysis, advanced age, overweight, less range of motion, and KL grade 1 at baseline were significantly associated with incident ROA. More flexion contracture, knee pain at baseline, poor physical function of lower limb measured by chair stand test tended to be statistically significant. After adjusting for age and gender, advanced age, female, overweight, less ROM, and KL grade 1 at baseline were significantly associated with incident ROA. The significant risk factors (including flexion

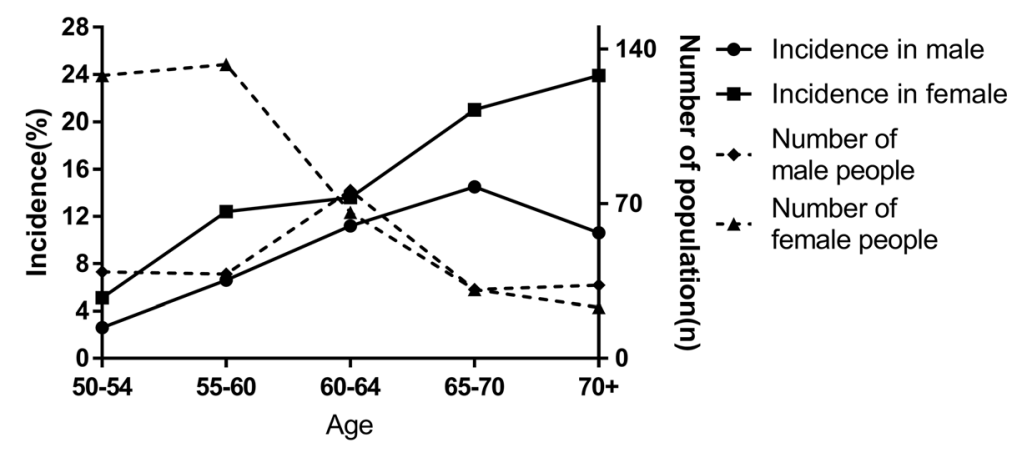

\section{Incidence of ROA and number of the subjects according to sex and age in knee level}

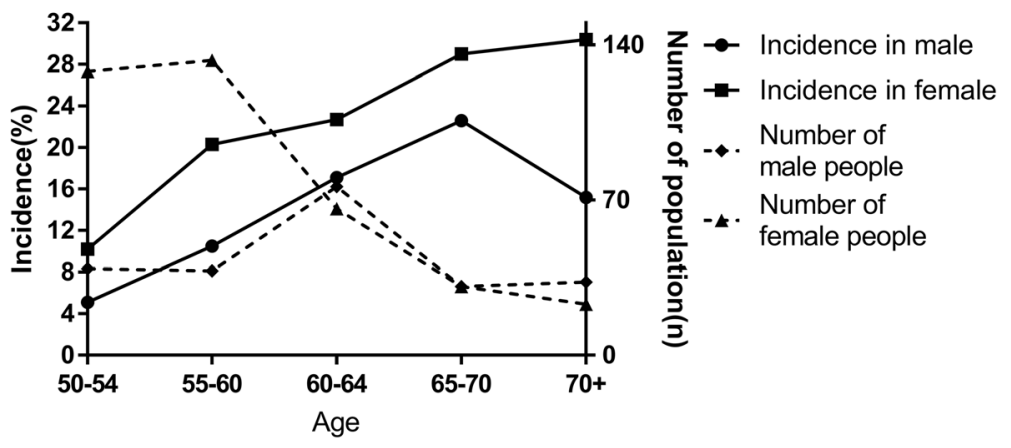

Incidence of ROA and number of the subjects according to sex and age in patient level

Fig. 1 Number of the subjects and incidence of ROA according to sex and age 
Table 2 Association between socio-demographic factors, physical function, baseline knee conditions, and incident ROA

\begin{tabular}{|c|c|c|c|c|c|c|c|c|}
\hline Characteristic & $\begin{array}{l}\text { Incident OA } \\
(n=102)\end{array}$ & $\begin{array}{l}\text { Non-incident OA } \\
(n=496)\end{array}$ & $\begin{array}{l}\text { Crude OR } \\
(95 \% \mathrm{Cl})\end{array}$ & $\begin{array}{l}P \\
\text { value }\end{array}$ & $\begin{array}{l}\text { Adjusted OR } \\
\text { (model 1) }(95 \% \mathrm{Cl})\end{array}$ & $\begin{array}{l}P \\
\text { value }\end{array}$ & $\begin{array}{l}\text { Adjusted OR } \\
\text { (model 2) }(95 \% \mathrm{Cl})\end{array}$ & $\begin{array}{l}P \\
\text { value }\end{array}$ \\
\hline \multicolumn{9}{|c|}{ Baseline socio-demographic, BMI, and history of knee injury } \\
\hline $\mathrm{Age}^{\mathrm{a}}$ & $61.15 \pm 6.37$ & $58.77 \pm 6.54$ & $\begin{array}{l}1.053(1.021- \\
1.087)\end{array}$ & $<0.01$ & $1.067(1.032-1.102)$ & $<0.01$ & $1.079(1.042-1.117)$ & $<0.01$ \\
\hline \multicolumn{9}{|l|}{ Gender $^{a}$} \\
\hline Male & $31(30.4 \%)$ & $186(37.5 \%)$ & 1.0 (reference) & & 1.0 (reference) & & 1.0 (reference) & \\
\hline Female & $71(69.6 \%)$ & $310(62.5 \%)$ & $\begin{array}{l}1.373(0.867- \\
2.174)\end{array}$ & 0.177 & $1.815(1.111-2.964)$ & 0.017 & $1.756(1.071-2.877)$ & 0.025 \\
\hline \multicolumn{9}{|l|}{$\mathrm{BMI}^{\mathrm{a}}$} \\
\hline Normal & $35(34.3 \%)$ & $224(45.25 \%)$ & 1.0 (reference) & & 1.0 (reference) & & & \\
\hline Overweight & $60(58.8 \%)$ & $225(45.4 \%)$ & $\begin{array}{l}1.699(1.076- \\
2.682)\end{array}$ & 0.023 & $2.072(1.278-3.358)$ & 0.003 & $2.086(1.286-3.385)$ & $<0.01$ \\
\hline Obesity & $7(6.9 \%)$ & $47(9.5 \%)$ & $\begin{array}{l}0.940(0.394- \\
2.246)\end{array}$ & 1.118 & $0.459(0.459-2.742)$ & 0.806 & $1.158(0.474-2.831)$ & 0.747 \\
\hline \multicolumn{9}{|l|}{ History of knee injury ${ }^{a}$} \\
\hline No & $97(95.1 \%)$ & $471(95 \%)$ & 1.0 (reference) & & 1.0 (reference) & & 1.0 (reference) & \\
\hline Yes & $5(4.9 \%)$ & $25(5 \%)$ & $\begin{array}{l}0.961(0.359- \\
2.572)\end{array}$ & 0.937 & $0.983(0.364-2.652)$ & 0.973 & $1.038(0.381-2.829)$ & 0.942 \\
\hline \multicolumn{9}{|l|}{ Education $^{a}$} \\
\hline Primary school & $19(18.6 \%)$ & $117(23.6 \%)$ & 1.0 (reference) & & 1.0 (reference) & & 1.0 (reference) & \\
\hline $\begin{array}{l}\text { Middle school or } \\
\text { above }\end{array}$ & $83(81.4 \%)$ & $379(76.4 \%)$ & $\begin{array}{l}1.351(0.787- \\
2.319)\end{array}$ & 0.275 & $1.320(0.764-2.283)$ & 0.32 & $1.329(0.764-2.313)$ & 0.314 \\
\hline \multicolumn{9}{|c|}{ Baseline physical function of the knee } \\
\hline Range of motion ${ }^{b}$ & $\begin{array}{l}128.27 \pm \\
7.10\end{array}$ & $129.95 \pm 6.46$ & $\begin{array}{l}0.955(0.930- \\
0.981)\end{array}$ & $<0.01$ & $0.954(0.928-0.981)$ & $<0.01$ & $0.952(0.923-0.983)$ & $<0.01$ \\
\hline Flexion contracture ${ }^{b}$ & $1.46 \pm 2.86$ & $1.19 \pm 2.15$ & $\begin{array}{l}1.071(0.999- \\
1.147)\end{array}$ & 0.052 & $1.072(0.998-1.151)$ & 0.058 & $1.068(0.993-1.150)$ & 0.078 \\
\hline 50 -foot walk test ${ }^{\mathrm{b}}$ & $13.14 \pm 2.86$ & $12.58 \pm 2.57$ & $\begin{array}{l}1.081(1.003- \\
1.164)\end{array}$ & 0.041 & $1.002(0.941-1.11)$ & 0.601 & $1.032(0.950-1.122)$ & 0.452 \\
\hline Chair stand test ${ }^{a}$ & $8.82 \pm 2.13$ & $8.37 \pm 2.20$ & $\begin{array}{l}1.087(0.994- \\
1.188)\end{array}$ & 0.066 & $1.056(0.962-1.159)$ & 0.252 & $1.056(0.960-1.161)$ & 0.265 \\
\hline
\end{tabular}

\section{Baseline knee joint condition in knee level}

Baseline $K / L$ grade ${ }^{b}$

\begin{tabular}{|c|c|c|c|c|c|c|c|c|}
\hline 0 & $90(44.1 \%)$ & 831 (83.8\%) & 1.0 (reference) & & 1.0 (reference) & & 1.0 (reference) & \\
\hline 1 & $114(55.9 \%)$ & $161(16.2 \%)$ & $\begin{array}{l}8.769(5.905- \\
13.022)\end{array}$ & $<0.01$ & $8.552(5.575-13.120)$ & $<0.01$ & 8.527 (5.489-13.246) & $<0.01$ \\
\hline \multicolumn{9}{|c|}{ Baseline knee pain ${ }^{b}$} \\
\hline No & 179 (87.7\%) & $900(90.7 \%)$ & 1.0 (reference) & & 1.0 (reference) & & 1.0 (reference) & \\
\hline Yes & $25(12.3 \%)$ & 92 (9.3\%) & $\begin{array}{l}1.646 \text { (0.970- } \\
2.793)\end{array}$ & 0.065 & $1.560(0.903-2.694)$ & 0.111 & $1.541(0.848-2.800)$ & 0.156 \\
\hline
\end{tabular}

Contralateral knee pain $^{b}$

\begin{tabular}{|c|c|c|c|c|c|c|c|c|}
\hline No & 179 (87.7\%) & 900 (90.7\%) & 1.0 (reference) & & 1.0 (reference) & & 1.0 (reference) & \\
\hline Yes & $25(12.3 \%)$ & 92 (9.3\%) & $\begin{array}{l}0.960(0.504- \\
1.831)\end{array}$ & 0.902 & $0.770(0.383-1.546)$ & 0.462 & $0.735(0.361-1.496)$ & 0.395 \\
\hline
\end{tabular}

Model 1: Adjusting for age and gender

Model 2: Adjusting for age, gender, BMI, education and history of injury

${ }^{\text {a }}$ Tested by Generalized Linear Model in patient level

${ }^{\mathrm{b}}$ Tested by Generalized Estimating Equation in knee level 


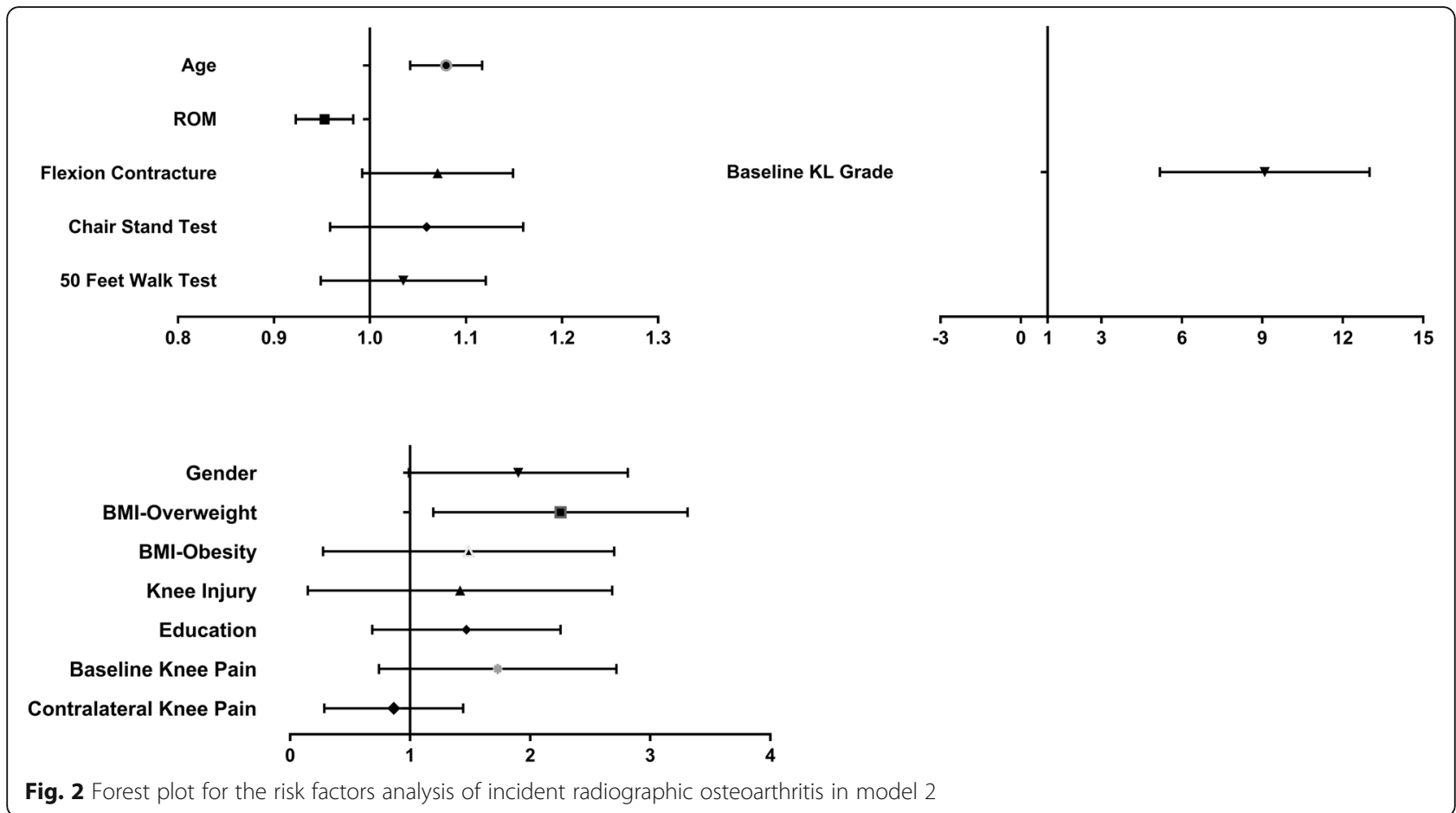

contracture) were the same after adjusting for age, gender, BMI, education level, and history of injury.

\section{Discussion}

To our knowledge, the current study is one of the first population-based, longitudinal, and prospective cohort studies demonstrating epidemiological characteristics and risk factors for knee OA in an elderly population in China. A total of 1295 residents were recruited at baseline in the year of 2014, and $962(74.3 \%)$ residents were followed in the year of 2017. We found that the incidence of ROA annually was 3.6\% in knee level and 5.7\% in patient level. Advanced age, overweight, less range of motion at baseline, and KL grade 1 at baseline were relevant risk factors for incident ROA.

The incidence reported in previous studies varied across countries and racial groups. It was reported that the incidence of knee OA was higher among Asian residents than among white population $[10,16,17]$. In the Framingham study with a mean follow-up interval of 8.1 years, the annual incidence of ROA was $1.4 \%$ in male and $2.2 \%$ in female in patient level [8]. While in Chingford Women's study, the incidence was $2.3 \%$ every year in knee level in the 5 years follow-up period [7]. In the research on osteoarthritis/osteoporosis against disability (ROAD) study in Japan, $6.9 \%$ male (2.1\% annually) and $11.9 \%$ female (3.6\% annually) developed incident ROA after 3.3 years from baseline visit [17]. In the Hallym Aging Study (HAS) in Korea, 3.1\% in male and 3.7\% in female suffered from incident ROA per year [10].
Compared with foreign research results, the incidence in our study was higher.

The higher progression rate of radiographic knee OA in our study might be due to the following reasons. First, our study had a higher follow-up rate $(74.5 \%)$ compared to previous studies (the Chingford study in the UK $55.9 \%$, the Framingham study in America 60.4\%, the ROAD study in Japan $74.4 \%$, the Hallym Aging Study (HAS) in Korea 63.9\%). It is generally believed that lower percentage of defaulters can bring less bias to the estimation of the incidence. Patients with severe osteoarthritis, with less walking ability, were much easier to be absent, which decreased the rate of the incidence. Second, the incidence of knee OA may have regional difference. Marita et al. found that the prevalence of knee OA was highest in the Asia Pacific developed region, followed by Oceania and North Africa/Middle East, and that was lowest in South and Southeast Asia. Most data of knee OA coming from developed countries, it was thought that there may be a high incidence in undeveloped and developing countries [18]. Third, our study investigated the population in suburban area, most of whom were farmers bearing heavy workload at their young age, which may raise the knee OA incidence in their elder age [8]. Although the average age of the population was 70.8 years old in Framingham study, 68.7 years old in ROAD study, 71 years old in HAS, which were much higher than that in the present research, we found that the incidence may decline with age in the elderly, especially in people over 70 years old 
according to our results in Fig. 1 and previous studies $[17,19]$. Taking all the above factors into consideration, we can draw the conclusion that the incidence in Beijing suburban area was higher.

Our study also found that advanced age, female, overweight, less range of motion, and KL grade 1 at baseline were significantly associated with incident ROA.

Advanced age, female, and higher BMI have long been viewed as main risk factors of ROA [20, 21]. Recently, a meta-analysis conducted by Silverwood showed that obesity, female gender, and previous knee injury were the main factors associated with onset of knee pain [20]. In most studies, incidence of ROA had positive correlation with age. However, our study found that the rate of increase in the incidence slowed down or even decreased in elderly people over 70 years old. There were few studies which also demonstrated a continuously increasing risk of knee and hip OA after the age of 40 for both genders, peaking at ages $75-80$, and falling back over 80 [19].

Less $\mathrm{ROM}$ is also a significant risk factor for incident knee osteoarthritis. Akinobu Nishimura firstly reported the relationship between ROM and ROA [11]. They found that a low knee ROM was the only risk factor for progressive knee OA. In particular, OA progressed more quickly among participants with a knee ROM of $<120^{\circ}$ than among those with a knee $\mathrm{ROM}$ of $>120^{\circ}$.In another study, Reijman et al. reported that restricting hip flexion by $>20 \%$ is a risk factor of progressive hip OA [22]. The same mechanism involved in hip OA might also function in knee OA because the knees are also weightbearing joints. However, it is not entirely clear how low knee ROM causes knee OA to progress, and the relevant mechanism needs further study. Special attention should be paid to the patients with low ROM, and effective measures should be taken to prevent knee OA progression.

Some investigators claimed that subjects with KL grade 1 at baseline should be treated differently because those doubtful osteophytes highly predict $\mathrm{OA}$ in the near future $[23,24]$. In this study, we found that KL grade 1 at baseline was strongly associated with radiograph progression of knee OA. In 2014, establishing the ROA prognostic model, Kerkhof found that adding the knee baseline KL grade significantly increased the AUC, which showed that knee baseline KL grade was a very strong predictor of future knee OA [24]. A KL grade of 1 was by far the best predictor of future knee OA, and even stronger than age, gender, and BMI. The most likely explanation for the strong predictive value of these minor radiographic changes is that this score is an indicator of early-stage $\mathrm{OA}$ and suggests that some structural damage has already occurred. Therefore, the probability of progression to a definite knee OA (KL $\geq$
2) is higher compared with people without any signs of $\mathrm{OA}$ on a radiograph.

Knee joint osteoarthritis is often accompanied by flexion contracture (FC). Our study found that flexion contracture tended to be statistically significant in both univariate and multivariate analysis, which showed that flexion contracture might be a risk factor for knee osteoarthritis incidence. Using the OAI data, Campbell found that knee FC was a risk factor for radiographic OA incidence, joint space narrowing, worse clinical outcomes, radiographic progression, and the need for early TKA [25]. Biomechanically, knee FC limits the cartilage surface concentrating loads over a smaller articular area, which potentially accelerates the cartilage damage due to the increasing local hydrostatic pressures, leading to chondrocyte apoptosis and further cartilage degeneration.

Frailty and low limb physical function has been proved to be associated with prevalent ROA [26]. Chair stand test and 50-foot walk were recommended by the Osteoarthritis Research Society International as the core set of performance-based measures. However, few studies have examined the association between low limb physical function and incident ROA. In our study, we found that the result of chair stand test, 50-foot walk were not statistically significant after adjusting basic demographic information.

A study conducted in symptomatic population showed that a 3-year-cumulative incidence of ROA with pain was $21.7 \%$, which was pretty higher compared with the study mentioned above conducted in normal population, proving the relationship of pain and ROA [27]. Baseline knee pain has been proved to be related with a reduction in thigh muscles strength, and it is well accepted that strong thigh muscles are able to reduce the incidence of OA $[28,29]$. Some researchers believe that baseline knee pain can be a promotive factor for the disease. However, a previous prospective study concluded that widespread pain including pain on either knee joint was not significantly associated with either incident unilateral or bilateral ROA [30]. In our study, we found that baseline knee pain was not significantly associated with incidence of ROA. The relationship between the two remains a controversial issue and still needs further study.

Injury in young age has been proved to be a risk factor related to osteoarthritis except for non-specific injury $[31,32]$. In the present study, there was no significant correlation between injury history and incidence of ROA. This was inconsistent with findings in previous studies. Sayre et al. reported that there was no evidence that history of non-specific injury (NSI) affects knee ROA incidence and progression in a population with knee pain, adjusting for SI, age, sex, BMI, KL grade, and follow-up time, while specific injury relating to cruciate ligament tear, collateral ligament tear, meniscal tear, or 
patellar injury was associated with increased incidence of ROA [31]. If confirmed, the null finding means that people who suffer non-specific injuries to the knee (no apparent damage to ligaments, meniscus or patella) need not worry about a subsequent, long-term, increased risk of radiographic OA incidence/progression, even when the NSI is severe enough to require a walking aid for at least 1 week. This result is important, as an increasing popularity of physical exercise may lead to more knee injuries, both specific and nonspecific. In addition, those who are overweight and are asked to begin exercise programs (which ought to reduce rates of ROA) represent another growing group at risk for knee injury.

With regard to low education level, it is widespread accepted to be associated with prevalence and progression of osteoarthritis [33, 34]. According to our study and previous foreign study, it may account for ROA prevalence and progression instead of incidence, for the higher education attainment may be more helpful for selfmanagement in the early stage of osteoarthritis patients.

\section{Strengths and limitations}

Our study had strengths and limitations. First, to our knowledge, our study was one of the first prospective study to investigate the incidence of knee ROA in China. We found that the incidence in Beijing suburban area was higher than those in other published regions. Second, we identified risk factors in demographic information, physical examination, physical function test, and imaging, which may offer more evidence-based policymaking for prevention and treatment of ROA. We found that advanced age, overweight, less range of motion, and $\mathrm{KL}$ grade 1 at baseline were relevant risk factors for incident ROA. However, despite its prospective design, 3 years is a rather short time to evaluate the progression of OA. Our study contains a relatively small sample size and a high percentage of female samples, which may cause difficulties in risk factors analysis and overestimate the incidence rate of OA. Some subjects with poor walk ability were more likely to be lost in the follow-up, which may bring bias for evaluation for both rate and factors. All the subjects came from Zhaoquanying, a small town in the suburban area around Beijing, may reduce the representativeness of the sample.

\section{Conclusion}

The incidence of knee ROA in Chinese suburban area was high. Advanced age, female, overweight, less range of motion, and KL grade 1 at baseline were associated with an increased risk of incident ROA.

\section{Abbreviations}

OA: Osteoarthritis; ROA: Radiographic osteoarthritis; KL: Kellgren and Lawrence; OAl: The Osteoarthritis Initiative; BMI: Body mass index;
SD: Standard deviation; ROM: Range of motion; NSI: Non-specific injury; FC: Flexion contracture

\section{Acknowledgements}

We would like to thank the OAI participants, OAI investigators and OAI Clinical Center's staff for generating this publicly available data set.

\section{Authors' contributions}

$J \mathrm{~L}$ and $\mathrm{QL}$ designed the study. $\mathrm{LZ}, \mathrm{CL}$, and $\mathrm{QL}$ analyzed the data and wrote the manuscript. JG and YH participated in the data collection, analysis, and interpretation. All authors read and approved the final manuscript.

\section{Funding}

This study was supported by National Key R\&D Program (2020YFC2004904) and Technology Science and Technology Major Projects of Beijing Municipal Science and Technology Commission of China (D171100003217000,

D171100003217002, Z181100001618020)

Availability of data and materials

Data will be available upon request by the first author $L Z$.

\section{Declarations}

Ethics approval and consent to participate

This study was approved by the ethics committee of the Peking University People's Hospital. Written informed consent was obtained from all participants according to the Declaration of Helsinki.

Consent for publication

Not applicable.

\section{Competing interests}

The authors declare that they have no competing interests.

\section{Author details}

${ }^{1}$ Arthritis Clinic and Research Center, Peking University People's Hospital, Peking University, No. 11 Xizhimen South Road, Xicheng District, Beijing 100044, China. ${ }^{2}$ Arthritis Institute, Peking University, Beijing, China.

${ }^{3}$ Department of Thoracic Surgery, Peking University Third Hospital, Peking University, Beijing, China.

Received: 15 May 2021 Accepted: 24 June 2021

Published online: 31 July 2021

\section{References}

1. Hawker GA, Croxford R, Bierman AS, Harvey PJ, Ravi B, Stanaitis I, et al. Allcause mortality and serious cardiovascular events in people with hip and knee osteoarthritis: a population based cohort study. PLoS One. 2014;9(3): e91286. https://doi.org/10.1371/journal.pone.0091286.

2. Liu Q, Niu J, Li H, Ke Y, Li R, Zhang Y, et al. Knee symptomatic osteoarthritis, walking disability, NSAIDs use and all-cause mortality: population-based Wuchuan Osteoarthritis Study. Sci Rep. 2017;7(1):3309. https://doi.org/10.103 8/s41598-017-03110-3.

3. Zambon S, Siviero P, Denkinger M, Limongi F, Victoria Castell M, van der Pas $S$, et al. Role of osteoarthritis, comorbidity, and pain in determining functional limitations in older populations: European project on osteoarthritis. Arthritis Care Res. 2016;68(6):801-10. https://doi.org/10.1002/a cr.22755.

4. Wallace IJ, Worthington S, Felson DT, Jurmain RD, Wren KT, Maijanen $H$, et al. Knee osteoarthritis has doubled in prevalence since the mid-20th century. Proc Natl Acad Sci U S A. 2017;114(35):9332-6. https://doi.org/10.1 073/pnas.1703856114

5. Murray CJ, Vos T, Lozano R, Naghavi M, Flaxman AD, Michaud C, et al. Disability-adjusted life years (DALYs) for 291 diseases and injuries in 21 regions, 1990-2010: a systematic analysis for the Global Burden of Disease Study 2010. Lancet. 2012;380(9859):2197-223.

6. Mediouni M, Schlatterer DR, Madry H, Cucchiarini M, Rai B. A review of translational medicine. The future paradigm: how can we connect the orthopedic dots better? Curr Med Res Opin. 2018;34(7):1217-29. https://doi. org/10.1080/03007995.2017.1385450. 
7. Hart DJ, Doyle DV, Spector TD. Association between metabolic factors and knee osteoarthritis in women: the Chingford Study. J Rheumatol. 1995;22(6): $1118-23$.

8. McAlindon TE, Wilson PW, Aliabadi P, Weissman B, Felson DT. Level of physical activity and the risk of radiographic and symptomatic knee osteoarthritis in the elderly: the Framingham study. Am J Med. 1999;106(2): 151-7. https://doi.org/10.1016/S0002-9343(98)00413-6.

9. Cooper C, Snow S, McAlindon TE, Kellingray S, Stuart B, Coggon D, et al. Risk factors for the incidence and progression of radiographic knee osteoarthritis. Arthritis Rheum. 2000;43(5):995-1000. https://doi.org/10.1 002/1529-0131(200005)43:5<995::AID-ANR6>3.0.CO;2-1.

10. Yoo JJ, Kim DH, Kim HA. Risk factors for progression of radiographic knee osteoarthritis in elderly community residents in Korea. BMC Musculoskelet Disord. 2018;19(1):80. https://doi.org/10.1186/s12891-018-1999-5.

11. Nishimura A, Hasegawa M, Kato K, Yamada T, Uchida A, Sudo A. Risk factors for the incidence and progression of radiographic osteoarthritis of the knee among Japanese. Int Orthop. 2011;35(6):839-43. https://doi.org/10.1007/ s00264-010-1073-x.

12. Felson DT, McAlindon TE, Anderson JJ, Naimark A, Weissman BW Aliabadi $P$, et al. Defining radiographic osteoarthritis for the whole knee. Osteoarthr Cartil. 1997;5(4):241-50. https://doi.org/10.1016/S1063-4 584(97)80020-9.

13. Zhang Y, Xu L, Nevitt MC, Aliabadi P, Yu W, Qin M, et al. Comparison of the prevalence of knee osteoarthritis between the elderly Chinese population in Beijing and whites in the United States: the Beijing Osteoarthritis Study. Arthritis Rheum. 2001;44(9):2065-71. https://doi.org/10.1002/1529-0131(2001 09)44:9<2065:.:AID-ART356>3.0.CO;2-Z.

14. Segal NA, Boyer ER, Wallace R, Torner JC, Yack HJ. Association between chair stand strategy and mobility limitations in older adults with symptomatic knee osteoarthritis. Arch Phys Med Rehabil. 2013;94(2):375-83. https://doi.org/10.1016/j.apmr.2012.09.026.

15. Unver B, Kalkan S, Yuksel E, Kahraman T, Karatosun V. Reliability of the 50-foot walk test and 30-sec chair stand test in total knee arthroplasty. Acta Ortop Bras. 2015;23(4):184-7. https://doi.org/10.1590/1413-7852201 5230401018

16. Felson DT, Zhang Y, Hannan MT, Naimark A, Weissman BN, Aliabadi P, et al. The incidence and natural history of knee osteoarthritis in the elderly. The Framingham Osteoarthritis Study. Arthritis Rheum. 1995;38(10):1500-5. https://doi.org/10.1002/art.1780381017.

17. Muraki S, Akune T, Oka H, Ishimoto Y, Nagata K, Yoshida M, et al. Incidence and risk factors for radiographic knee osteoarthritis and knee pain in Japanese men and women: a longitudinal population-based cohort study. Arthritis Rheum. 2012;64(5):1447-56. https://doi.org/10.1002/art.33508.

18. Cross M, Smith E, Hoy D, Nolte S, Ackerman I, Fransen M, et al. The global burden of hip and knee osteoarthritis: estimates from the global burden of disease 2010 study. Ann Rheum Dis. 2014;73(7):1323-30. https://doi.org/1 0.1136/annrheumdis-2013-204763

19. Prieto-Alhambra D, Judge A, Javaid MK, Cooper C, Diez-Perez A, Arden NK Incidence and risk factors for clinically diagnosed knee, hip and hand osteoarthritis: influences of age, gender and osteoarthritis affecting other joints. Ann Rheum Dis. 2014;73(9):1659-64. https://doi.org/10.1136/a nnrheumdis-2013-203355.

20. Silverwood V, Blagojevic-Bucknall M, Jinks C, Jordan JL, Protheroe J, Jordan KP. Current evidence on risk factors for knee osteoarthritis in older adults: a systematic review and meta-analysis. Osteoarthr Cartil. 2015;23(4):507-15. https://doi.org/10.1016/j.joca.2014.11.019.

21. Blagojevic $M$, Jinks $C$, Jeffery $A$, Jordan KP. Risk factors for onset of osteoarthritis of the knee in older adults: a systematic review and metaanalysis. Osteoarthr Cartil. 2010;18(1):24-33. https://doi.org/10.1016/j.joca.2 009.08.010.

22. Reijman M, Hazes JM, Pols HA, Bernsen RM, Koes BW, Bierma-Zeinstra SM. Role of radiography in predicting progression of osteoarthritis of the hip: prospective cohort study. BMJ. 2005;330(7501):1183.

23. Leyland KM, Hart DJ, Javaid MK, Judge A, Kiran A, Soni A, et al. The natural history of radiographic knee osteoarthritis: a fourteen-year population-based cohort study. Arthritis Rheum. 2012;64(7):2243-51. https://doi.org/10.1002/a rt.34415.

24. Kerkhof HJ, Bierma-Zeinstra SM, Arden NK, Metrustry S, Castano-Betancourt M, Hart DJ, et al. Prediction model for knee osteoarthritis incidence, including clinical, genetic and biochemical risk factors. Ann Rheum Dis. 2014;73(12):2116-21. https://doi.org/10.1136/annrheumdis-2013-203620.
25. Campbell TM, McGonagle D. Flexion contracture is a risk factor for knee osteoarthritis incidence, progression and earlier arthroplasty: data from the osteoarthritis initiative. Ann Phys Rehabil Med. 2021;64(2):101439. https://doi. org/10.1016/j.rehab.2020.09.005.

26. Misra D, Felson DT, Silliman RA, Nevitt M, Lewis CE, Torner J, et al. Knee osteoarthritis and frailty: findings from the Multicenter Osteoarthritis Study and Osteoarthritis Initiative. J Gerontol A Biol Sci Med Sci. 2015;70(3):339-44. https://doi.org/10.1093/gerona/glu102.

27. Duncan R, Peat G, Thomas E, Hay EM, Croft P. Incidence, progression and sequence of development of radiographic knee osteoarthritis in a symptomatic population. Ann Rheum Dis. 2011;70(11):1944-8. https://doi. org/10.1136/ard.2011.151050

28. Ruhdorfer A, Wirth W, Eckstein F. Association of knee pain with a reduction in thigh muscle strength - a cross-sectional analysis including 4553 osteoarthritis initiative participants. Osteoarthr Cartil. 2017:25(5):658-66. https://doi.org/10.1016/j.joca.2016.10.026.

29. Segal NA, Glass NA. Is quadriceps muscle weakness a risk factor for incident or progressive knee osteoarthritis? Phys Sportsmed. 2011;39(4):44-50. https://doi.org/10.3810/psm.2011.11.1938.

30. Carlesso LC, Niu J, Segal NA, Frey-Law LA, Lewis CE, Nevitt MC, et al. The effect of widespread pain on knee pain worsening, incident knee osteoarthritis (OA), and incident knee pain: the Multicenter OA (MOST) Study. J Rheumatol. 2017;44(4):493-8. https://doi.org/10.3899/jrheum.1 60853.

31. Sayre EC, Singer J, Thorne A, Wong H, Kopec JA, Esdaile JM, et al. Does moderate or severe nonspecific knee injury affect radiographic osteoarthritis incidence and progression? BMC Musculoskelet Disord. 2013;14(1):309. https://doi.org/10.1186/1471-2474-14-309.

32. Gelber AC, Hochberg MC, Mead LA, Wang NY, Wigley FM, Klag MJ. Joint injury in young adults and risk for subsequent knee and hip osteoarthritis. Ann Intern Med. 2000;133(5):321-8. https://doi.org/10.7326/0003-4819-1335-200009050-00007

33. Hannan MT, Anderson JJ, Pincus T, Felson DT. Educational attainment and osteoarthritis: differential associations with radiographic changes and symptom reporting. J Clin Epidemiol. 1992;45(2):139-47. https://doi.org/10.1 016/0895-4356(92)90006-9.

34. Callahan LF, Shreffler J, Siaton BC, Helmick CG, Schoster B, Schwartz TA et al. Limited educational attainment and radiographic and symptomatic knee osteoarthritis: a cross-sectional analysis using data from the Johnston County (North Carolina) Osteoarthritis Project. Arthr Res Ther. 2010;12(2):R46 https://doi.org/10.1186/ar2956.

\section{Publisher's Note}

Springer Nature remains neutral with regard to jurisdictional claims in published maps and institutional affiliations.

Ready to submit your research? Choose BMC and benefit from:

- fast, convenient online submission

- thorough peer review by experienced researchers in your field

- rapid publication on acceptance

- support for research data, including large and complex data types

- gold Open Access which fosters wider collaboration and increased citations

- maximum visibility for your research: over $100 \mathrm{M}$ website views per year

At $\mathrm{BMC}$, research is always in progress.

Learn more biomedcentral.com/submission 